\title{
Cement leakage and complication of liposarcoma spinal metastasis during vertebral augmentation procedure: a case report
}

\author{
Aykut Akpinar ${ }^{1}$, Necati Ucler ${ }^{1,2^{*}}$, Cem Seyho Yucetas ${ }^{1}$, Uzay Erdogan ${ }^{1}$ and Mehmet Davut Ucar ${ }^{1}$
}

\begin{abstract}
Background: Liposarcoma is a malignant tumor of soft tissue. Myxoid/round cell liposarcoma has a tendency to spread to extrapulmonary sites but the spine is an unusual location even for metastasis. Metastatic bone tumors in the spine are painful. The vertebral body augmentation procedures for treating painful metastatic spinal lesions are minimally invasive and are good alternatives to open surgery.

Case presentation: A 41-year-old Turkish man was treated with radiofrequency tumor ablation and percutaneous vertebral augmentation for spinal metastasis. Asymptomatic perivertebral and segmental veins' cement leakage was detected on perioperative X-ray radiograms; at the follow-up computed tomography scan, no further migration of any cement material was seen, and his postoperative course was uneventful.

Conclusions: The risk of cement leakage and embolism is increased with the treatment of some malignant lesions. The frequency of local leakage of bone cement is relatively high. Patients undergoing percutaneous vertebral augmentation of malignant spinal metastases need close monitoring. There is no agreement on the treatment strategy.
\end{abstract}

Keywords: Cement leakage, Myxoid round cell liposarcoma, Radiofrequency tumor ablation, Spinal metastasis, Vertebral augmentation

\section{Background}

Liposarcoma is one of the most common histologic types of soft tissue sarcoma [1]. The frequency of myxoid/round cell liposarcoma (MRCL) metastasis to bone is not clear [2], but the incidence in one series was reported to be $17 \%$ $[1,2]$. The round cells $(>5 \%)$ are considered high grade [1]. The patients were followed up clinically with computed tomography (CT) or chest X-ray surveillance for metastasis. Magnetic resonance imaging (MRI) provides the most sensitive technique for the diagnosis of bone metastasis in MRCL [2].

Spine metastasis can be debilitating, and have a significant impact on patients' quality of life. The treatment

\footnotetext{
* Correspondence: necati_ucler@yahoo.com

${ }^{1}$ Department of Neurosurgery, Adiyaman University Education and Research Hospital, Adiyaman, Turkey

${ }^{2}$ Department of Neurosurgery, School of Medicine, Adiyaman University, Adiyaman 02200, Turkey
}

(c) 2016 Akpinar et al. Open Access This article is distributed under the terms of the Creative Commons Attribution 4.0 International License (http://creativecommons.org/licenses/by/4.0/), which permits unrestricted use, distribution, and reproduction in any medium, provided you give appropriate credit to the original author(s) and the source, provide a link to the Creative Commons license, and indicate if changes were made. The Creative Commons Public Domain Dedication waiver (http://creativecommons.org/publicdomain/zero/1.0/) applies to the data made available in this article, unless otherwise stated. regimen for spinal metastasis is generally palliative and consists of a combination of medical therapies (steroids, pain medication, chemotherapy, radiation therapy, and surgery). Radiofrequency thermal ablation (Rf-TA) and vertebral augmentation procedures (VAPs) have been shown to be effective in metastatic bone lesions $[3,4]$. Our patient received vertebral augmentation with highviscosity cement after use of Rf-TA. Although relatively safe, the procedure is not without risks.

\section{Case presentation}

We describe the case of a 41-year-old Turkish man. Eight months before he was admitted to our clinic, a subcutaneous tissue mass was excised with a marginal excision from his right thigh; it was liposarcoma. He then received chemotherapy and radiotherapy with a good response but the liposarcoma had since progressed. 
He was admitted to our hospital, presenting with back pain with radiation and with no neurological deficits. $\mathrm{He}$ had a 3-month history of increased back pain, and he did not recall any trauma. A skeletal survey showed no lytic lesions, and a CT scan also showed no evidence of tumors in his spine. A spinal MRI revealed multilevel vertebral body edema (a low signal was seen within the body of his lumbar and thoracic vertebrae, on T1 corresponding to high signal on T2, in keeping with an interosseous metastasis; Fig. 1). A CT scan of his chest showed lung metastasis. There was no cord compression. After he and his family gave us written informed consent, Rf-TA and VAP were performed.

\section{Surgical technique}

Under spinal anesthesia in a prone position, this procedure was also performed with bi-plane fluoroscopy through a transpedicular approach by placement of working cannulas unilaterally. Through the working cannula, a drill and curette were used to create a tract and a cavity at the center of L2 to L4 vertebral bodies. The procedure was performed under fluoroscopic guidance and Rf-TA (50 to $80{ }^{\circ} \mathrm{C}, 10$ minutes; Fig. 2) was made. We then injected high viscosity bone cement at low pressure into the ablated tumor bed. The bone cement injection was monitored with continuous fluoroscopy. When leakage was noted, the application was stopped
(Fig. 3). In total, $4 \mathrm{ml}$ cement had been released. Postoperative serum chemistries, arterial blood gas, and cardiac enzymes were normal and his postoperative course was uneventful. Cement leakage was observed in the perivertebral soft tissue, perivertebral venous system, and segmental vein.

Although our patient remained asymptomatic, he had $\mathrm{X}$-rays and CT scans prior to discharge on postoperative day 7. A repeat CT scan showed the characteristic appearance of cement leakage at the level of augmented vertebrae in the perivertebral venous system, segmental vein, epidural space, and soft tissue (Fig. 4). A follow-up CT scan showed no further migration of any cement material.

\section{Discussion}

The most common subtype of soft tissue sarcoma is liposarcoma, which constitutes 9.8 to $18 \%$ of cases [5]. The peak incidence of MRCL (male predominant) is in the fourth and fifth decades [5]. MRCL in particular tends to spread to other soft tissue sites, including the retroperitoneum, thorax, opposite extremity, and other soft tissue sites, before metastasis to lungs. The skeletal metastasis prevalence is unclear [6].

Early detection of metastasis can affect the quality of life of patients. Initial staging and follow-up studies should include chest $\mathrm{CT}$, bone scanning, abdominal and

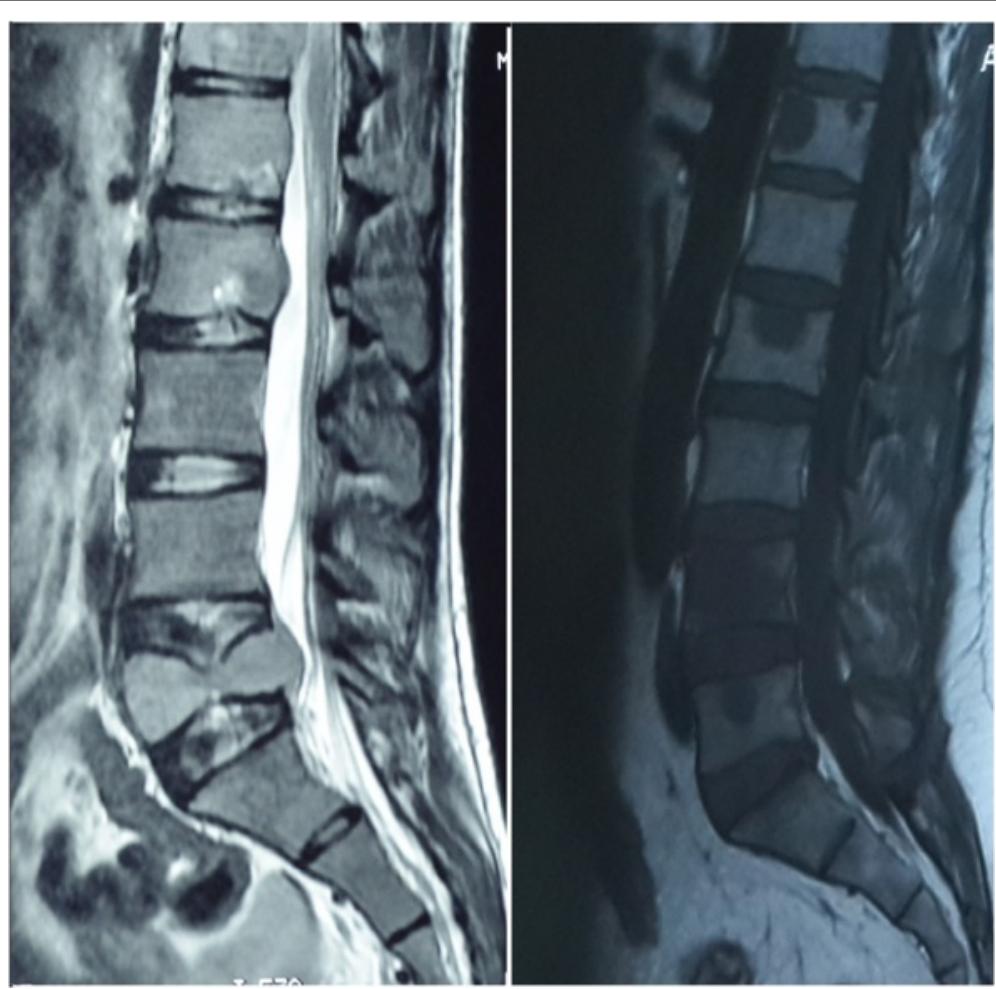

Fig. 1 Spinal preoperative T1-weighted and T2-weighted magnetic resonance imaging revealed multilevel vertebral body edema 


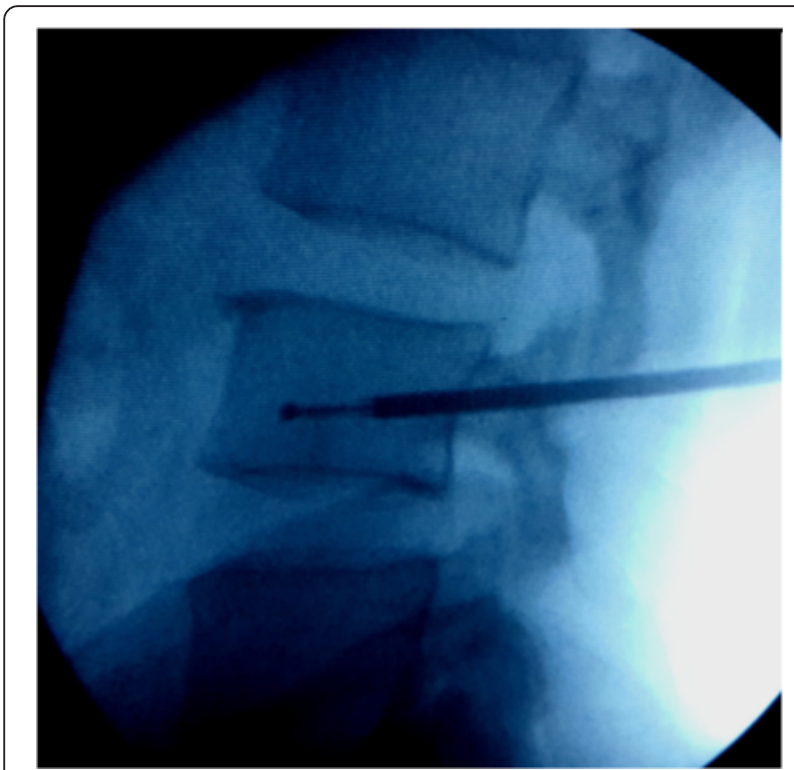

Fig. 2 The procedure was performed under fluoroscopic guidance, and thermal ablation (50 to $80{ }^{\circ} \mathrm{C}, 10$ minutes) was made

pelvic CT, and MRI. For bone metastasis, MRI is the investigation of choice [2]. Although intensive multimodality therapy has prolonged the survival of patients with musculoskeletal sarcomas, the prognosis of patients with metastatic disease is still poor. The reason for this is the high incidence of extrapulmonary metastases.

Rf-TA and VAP have been shown to be effective in metastatic bone lesions [3, 4]. Despite the high rate of success with VAPs, perioperative and postoperative complications are encountered mostly from cement leakage

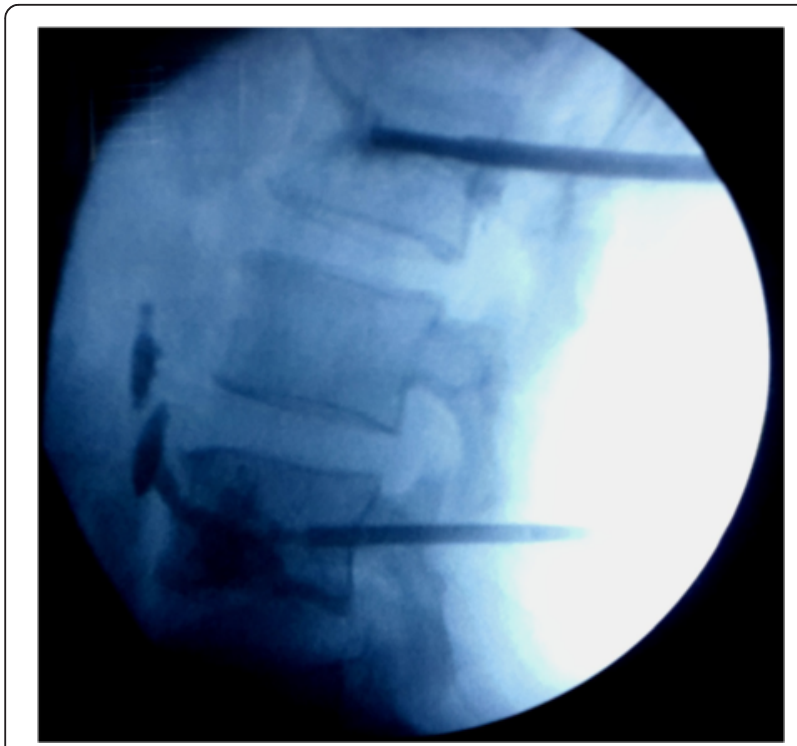

Fig. 3 The fluoroscopic image showing cement leakage into the surrounding tissues and systemic circulation. The frequency of local leakage of bone cement is high (63 to $81 \%$ ) [7]. Moreover, the rate of perivertebral venous leakage is $88 \%$ [7]. Discal leakage (34\%) with consequent pulmonary cement embolism varies from 4.6 to $6.8 \%$ (up to $26 \%$ in radiologic studies) [8, 9]. Cement leakage into the paravertebral veins, and pulmonary, cerebral, and cardiac embolism are severe complications [7-10]. As a result of bone cement leakage into venous channels, lethal conditions such as pulmonary embolism can occur, with rates ranging from 0.6 to $0.01 \%$ [11]. Cement leakage into the paravertebral soft tissue (6 to $52 \%)$ and intervertebral disc space, increasing pain, hypotension, and new fracture risk are mild complications [12]. Infection, misplaced needle, and epidural and foraminal space cement leakage (the prevalence may be as high as $40 \%)$ are moderate complications [12, 13]. The rates of neurological complications with VAPs were between 0.6 and $0.03 \%[11,13]$.

Bone cement leakage complications occur more often when treating patients with metastatic disease $(<10 \%)$ than those with osteoporosis (1 to $2 \%)$ or spinal angiomas (2 to $3 \%$ ). The higher risk of extravasation in patients with spinal malignancy is because of the cortical destruction of vertebral body and higher vascularization. Some authors reported the use of a preinjection venogram to decrease the incidence of pulmonary embolism [3, 4].

Conservative management with anticoagulants, antibiotics, and corticosteroids is reserved for smaller or peripherally located cement emboli. Paravertebral venous leakage and pulmonary embolization of cement occurs frequently but is clinically silent in most cases.

In our case, his visual analog scale (VAS) before the procedure was 7 and after the procedure it was 2 . In order to prevent or reduce cement leakage, we used high viscosity cement ( $4 \mathrm{ml}$ volume) and a low-pressure injection. Before injection, we created a cavity with a drill and curette but cement leakages still occurred. It appears that the cement passed from the vertebral venous plexuses via the paravertebral veins.

\section{Conclusions}

The vertebral augmentation with radiofrequency procedure significantly reduced associated spinal malignancy pain, improving functionality and quality of life. However, many patients' cement leakage remains asymptomatic, but late cement migration during follow-up did not occur in our case. Standard post-procedural CT scan of the treated vertebral body in vertebral augmentation is useful. Even though we used high viscosity cement and created a cavity, cement leakage did occur. Close monitoring of patients undergoing VAP and radiological follow-up are important. 


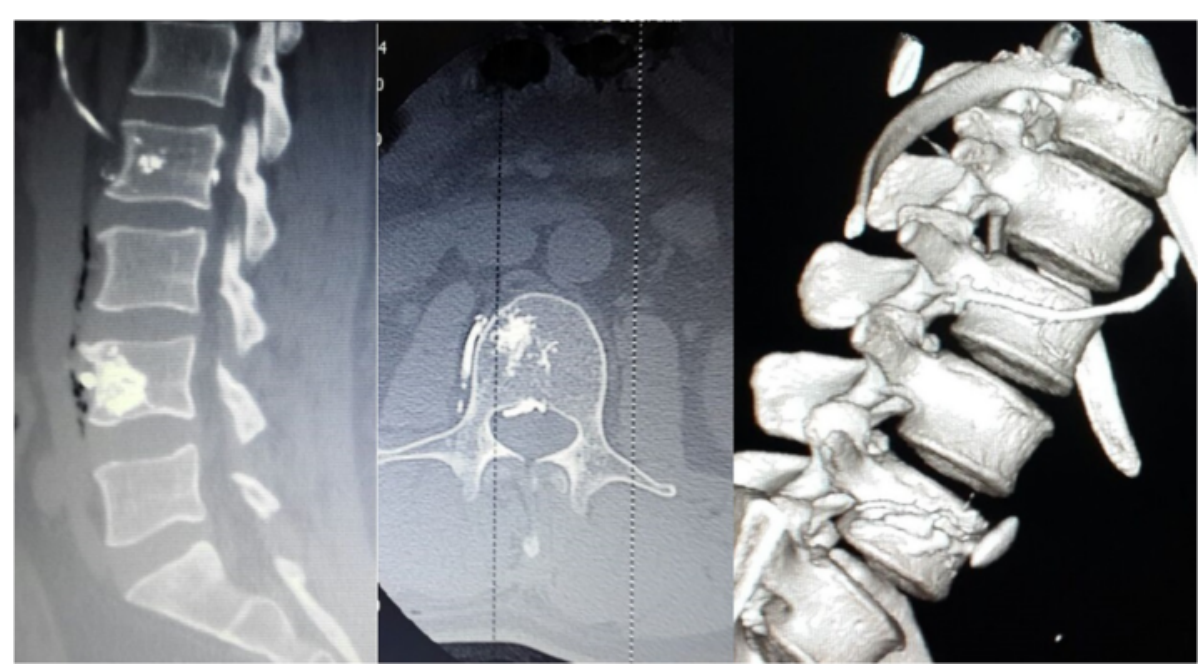

Fig. 4 A computed tomography scan showed the characteristic appearance of cement leakage at the level of augmented vertebrae in the perivertebral venous system, segmental vein, epidural space, and soft tissue

\section{Consent}

Written informed consent was obtained from the patient for publication of this case report and any accompanying images. A copy of the written consent is available for review by the Editor-in-Chief of this journal.

\section{Abbreviations}

CT: Computed tomography; MRCL: Myxoid/round cell liposarcoma; MRI: Magnetic resonance imaging; Rf-TA: Radiofrequency thermal ablation; VAPS: Vertebral augmentation procedures; VAS: Visual analog scale.

\section{Competing interests}

The authors declare that they have no competing interests.

\section{Authors' contributions}

$\mathrm{NU}, \mathrm{AA}$ and CSY wrote the manuscript, UE and MDU searched the references. All authors read and approved the final manuscript.

Received: 4 January 2016 Accepted: 11 February 2016

Published online: 24 February 2016

\section{References}

1. Noble JL, Moskovic E, Fisher C, Judson I. Imaging of skeletal metastases in myxoid liposarcoma. Sarcoma. 2010;2010:262361. doi:10.1155/2010/262361.Epub2010.

2. Schwab JH, Boland PJ, Antonescu C, Bilsky MH, Healey JH. Spinal metastases from myxoid liposarcoma warrant screening with magnetic resonance imaging. Cancer. 2007;110:1815-22.

3. Georgy BA. Metastatic spinal lesions: state-of-the-art treatment options and future trends. AJNR Am J Neuroradiol. 2008;29:1605-11. doi:10.3174/ajnr. A1137.Epub2008.

4. Masala S, Roselli M, Massari F, Fiori R, Ursone A, Fossile E, et al. Radiofrequency Heat Ablation and Vertebroplasty in the treatment of neoplastic vertebral body fractures. Anticancer Res. 2004;24:3129-33.

5. Enzinger FM, Weiss SW. Soft Tissue Tumors. 3rd ed. Pa: Mosby; 1995.

6. Estourgie SH, Nielsen GP, Ott MJ. Metastatic patterns of extremity myxoid liposarcoma and their outcome. J Surg Oncol. 2002;80:89-93.

7. Venmans A, Klazen CA, van Rooij WJ, de Vries J, Mali WP, Lohle PN. Postprocedural $C T$ for perivertebral cement leakage in percutaneous vertebroplasty is not necessary - results from VERTOS II. Neuroradiology. 2011;53:19-22. doi:10.1007/s00234-010-0705-6.Epub2010.

8. Geraci G, Lo lacono G, Lo Nigro C, Cannizzaro F, Cajozzo M, Modica G. Asymptomatic bone cement pulmonary embolism after vertebroplasty: case report and literature review. Case Rep Surg. 2013;2013:591432. doi:10.1155/ 2013/591432.Epub2013.

9. Lee IJ, Choi AL, Yie MY, Yoon JY, Jeon EY, Koh SH, et al. CT evaluation of local leakage of bone cement after percutaneous kyphoplasty and vertebroplasty. Acta Radiol. 2010;51:649-54. doi:10.3109/ 02841851003620366.

10. Krueger A, Bliemel C, Zettl R, Ruchholtz S. Management of pulmonary cement embolism after percutaneous vertebroplasty and kyphoplasty: a systematic review of the literature. Eur Spine J. 2009;18:1257-65. doi:10. 1007/s00586-009-1073-y.Epub2009.

11. Hulme PA, Krebs J, Ferguson SJ, Berlemann U. Vertebroplasty and kyphoplasty: a systematic review of 69 clinical studies. Spine (Phila Pa 1976). 2006;31:1983-2001.

12. Laredo JD, Hamze B. Complications of vertebroplasty and their prevention. Semin Ultrasound CT MR. 2005;26:65-80.

13. Lopes NM, Lopes VK. Paraplegia complicating percutaneous vertebroplasty for osteoporotic vertebral fracture: Case report. Arq Neuropsiquiatr. 2004;62:879.

Submit your next manuscript to BioMed Central and we will help you at every step:

- We accept pre-submission inquiries

- Our selector tool helps you to find the most relevant journal

- We provide round the clock customer support

- Convenient online submission

- Thorough peer review

- Inclusion in PubMed and all major indexing services

- Maximum visibility for your research

Submit your manuscript at www.biomedcentral.com/submit 